\section{Experimental Results of the QUENCH-16 Bundle Test on Air Ingress}

\author{
J. Stuckert, M. Steinbrück
}




\section{Oxidation in atmospheres containing nitrogen}

$\mathbb{N}$ II

Late phase after RPV failure

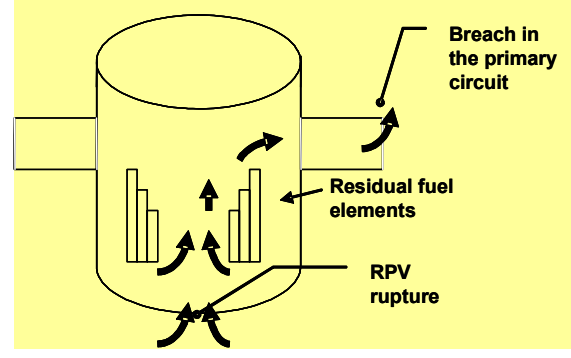

Mid loop operation

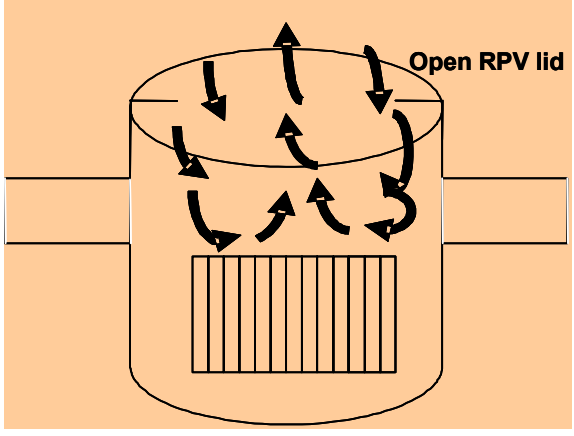

Spent fuel storage pool accident

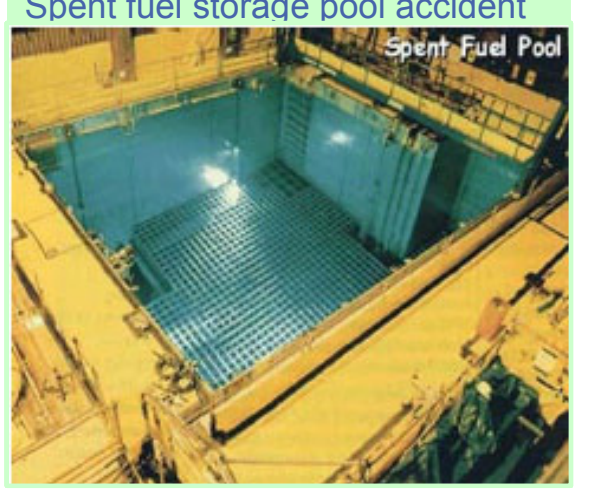




\section{Previous bundle air ingress experiments}

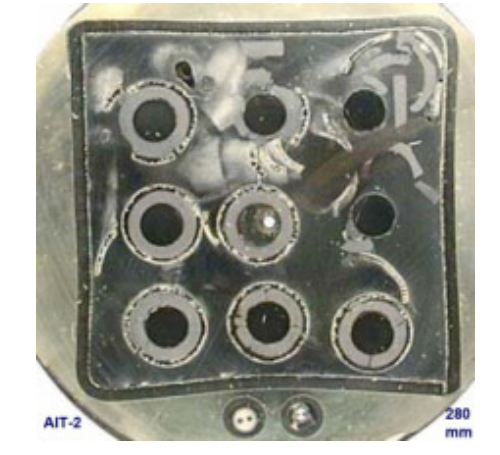

- CODEX AIT-1, AIT-2 (Zry-4) performed 1999 at AEKI/Budapest: small bundles with 9 rods

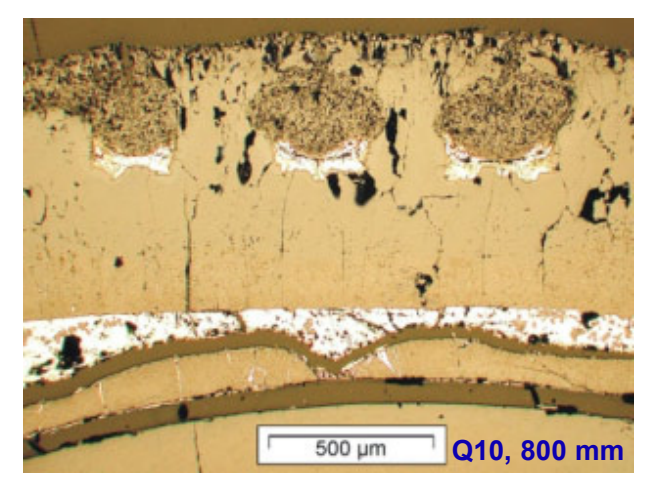

- QUENCH-10 (Zry-4 claddings) performed 2004 at $\mathrm{KIT} / \mathrm{Karls}$ ruhe: strong pre-oxidised bundle

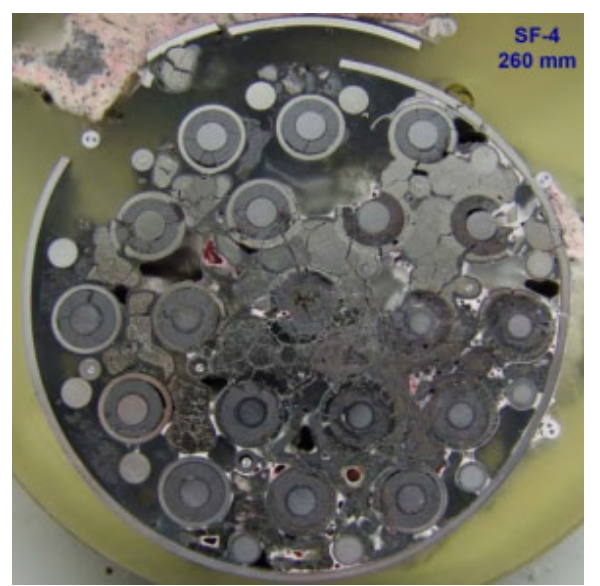

- PARAMETER-SF4 (E110 claddings) performed 2009 at LUCH/Podolsk: very high temperatures on reflood initiation with following escalation (bundle melting) 


\section{Objectives of the QUENCH-16 test}

- air oxidation after rather moderate pre-oxidation in steam;

- slow oxidation and nitriding of zirconium in high temperature air and transition to rapid oxidation and temperature excursion;

- role of nitrogen under oxygen-starved conditions,

- formation of oxide and nitride layers on the surface of $\mathrm{Zr}$;

- release of hydrogen from oxidised zirconium during air ingress scenario;

- reflooding of oxidised and nitrided bundle by water initiated at temperatures well below the melting point of the cladding, release of nitrogen. 


\section{QUENCH facility}

QUENCH-16 facility features:

1) controllable synthetic air input;

2) Krypton filling of rods;

3) temperature control for off-gas pipe (to avoid the steam condensation)

4) control of pressure in space between shroud and jacket

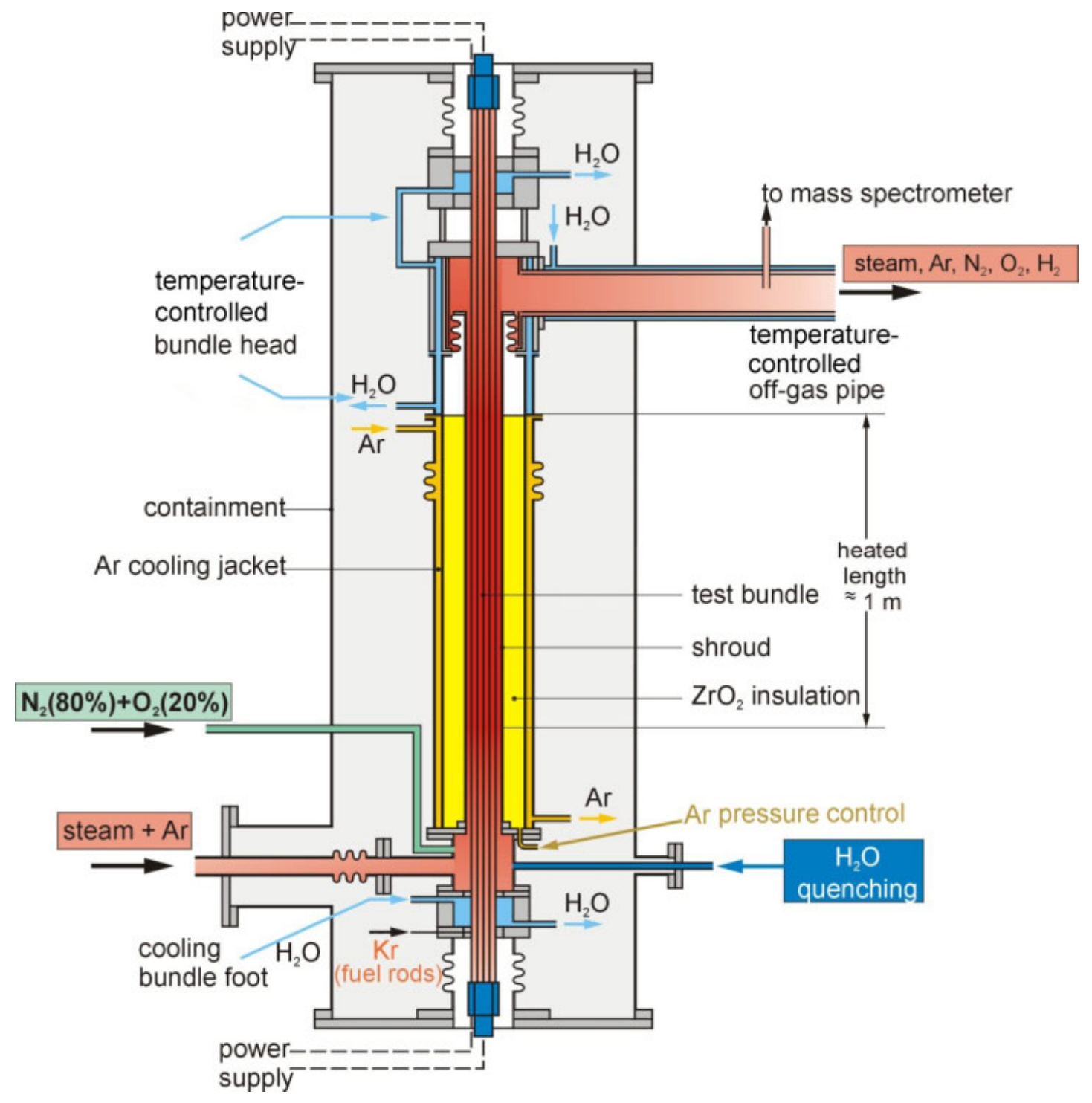




\section{Cross section of the PWR test column}

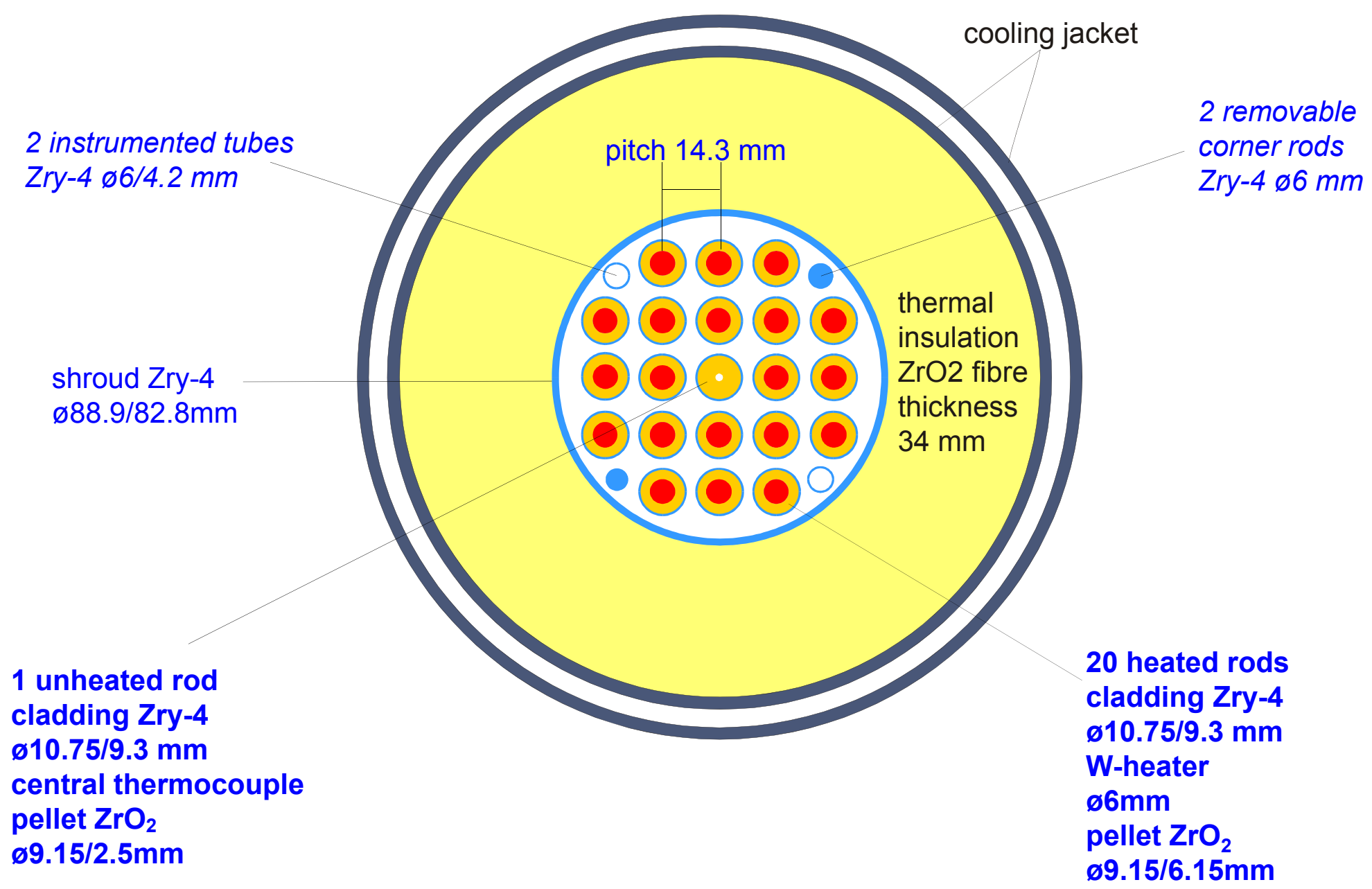




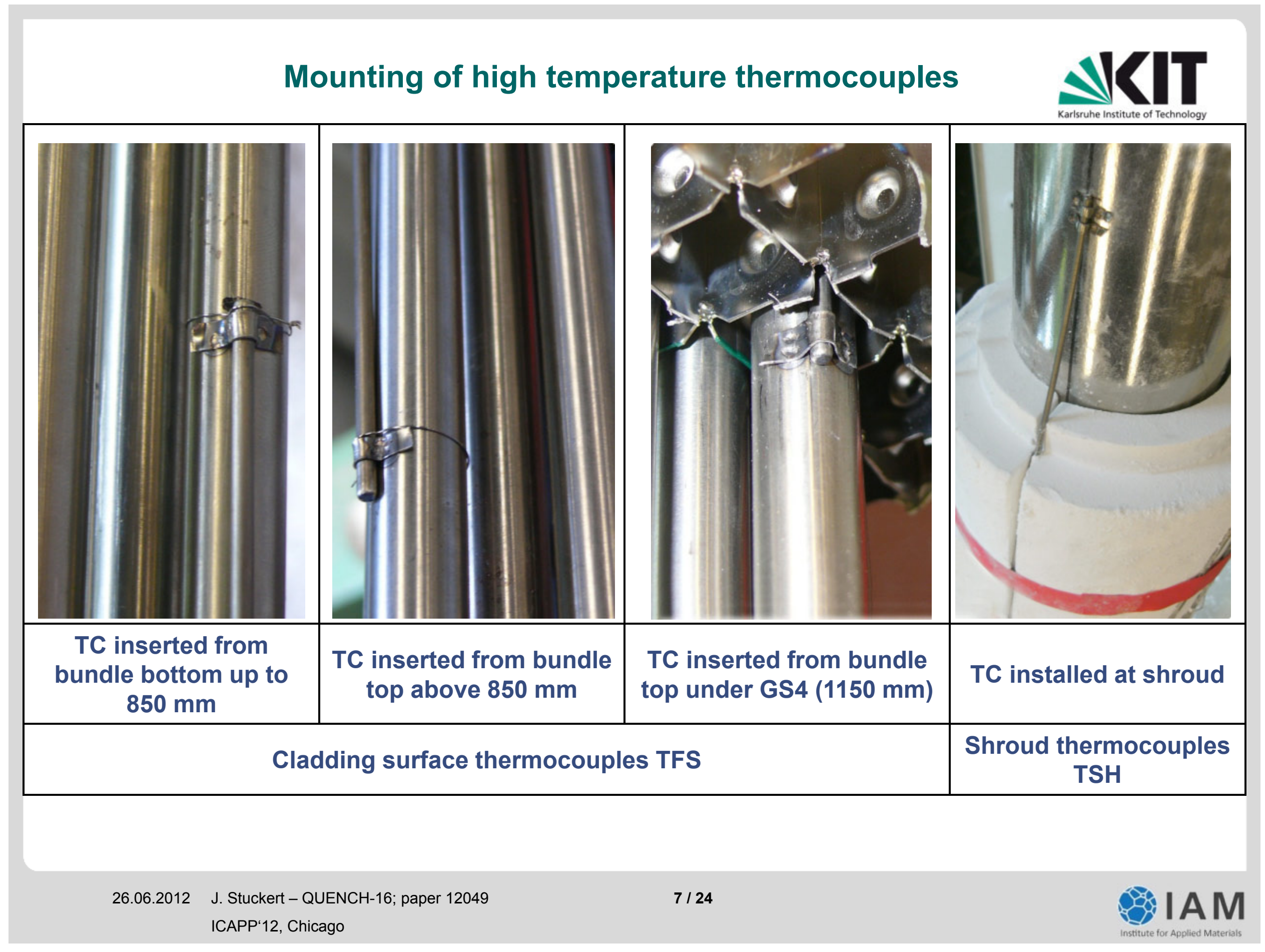




\section{QUENCH-16 test progression}

test performed on 27.07.2011 at KIT/IAM

according to pre-test calculations from PSI, GRS, EdF

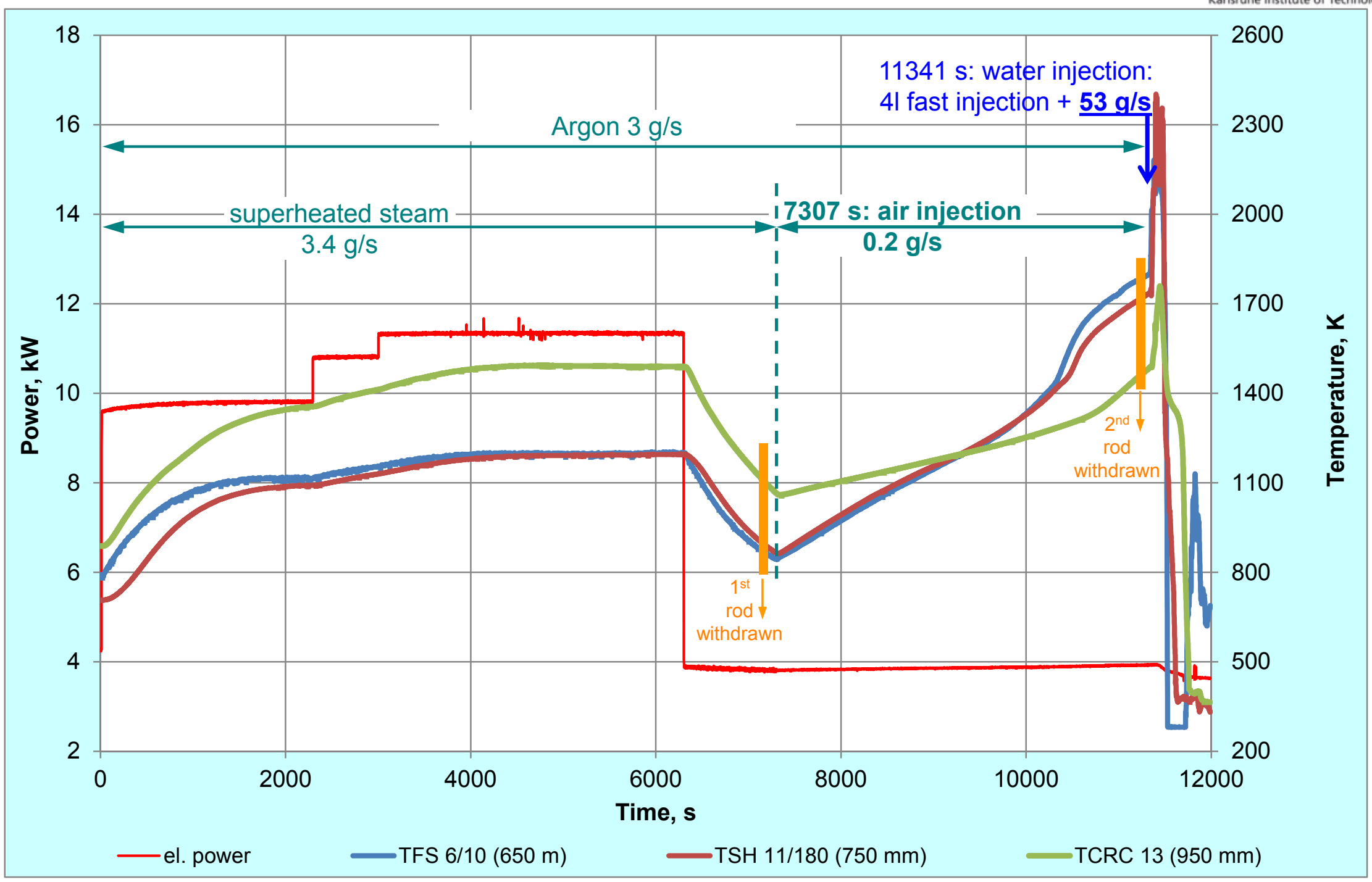


Consumption of nitrogen and oxygen during air ingress phase: data of mass spectrometer

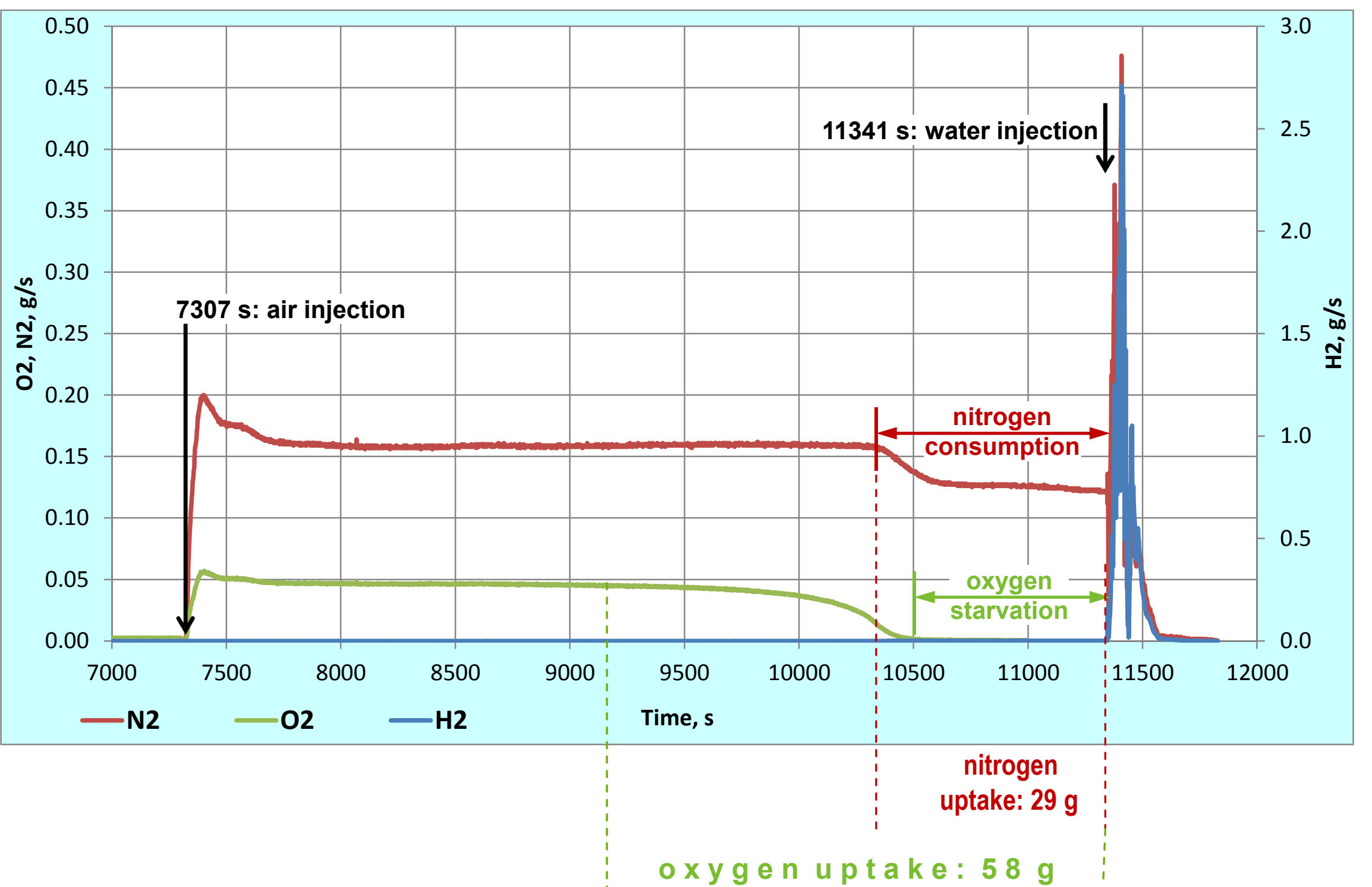




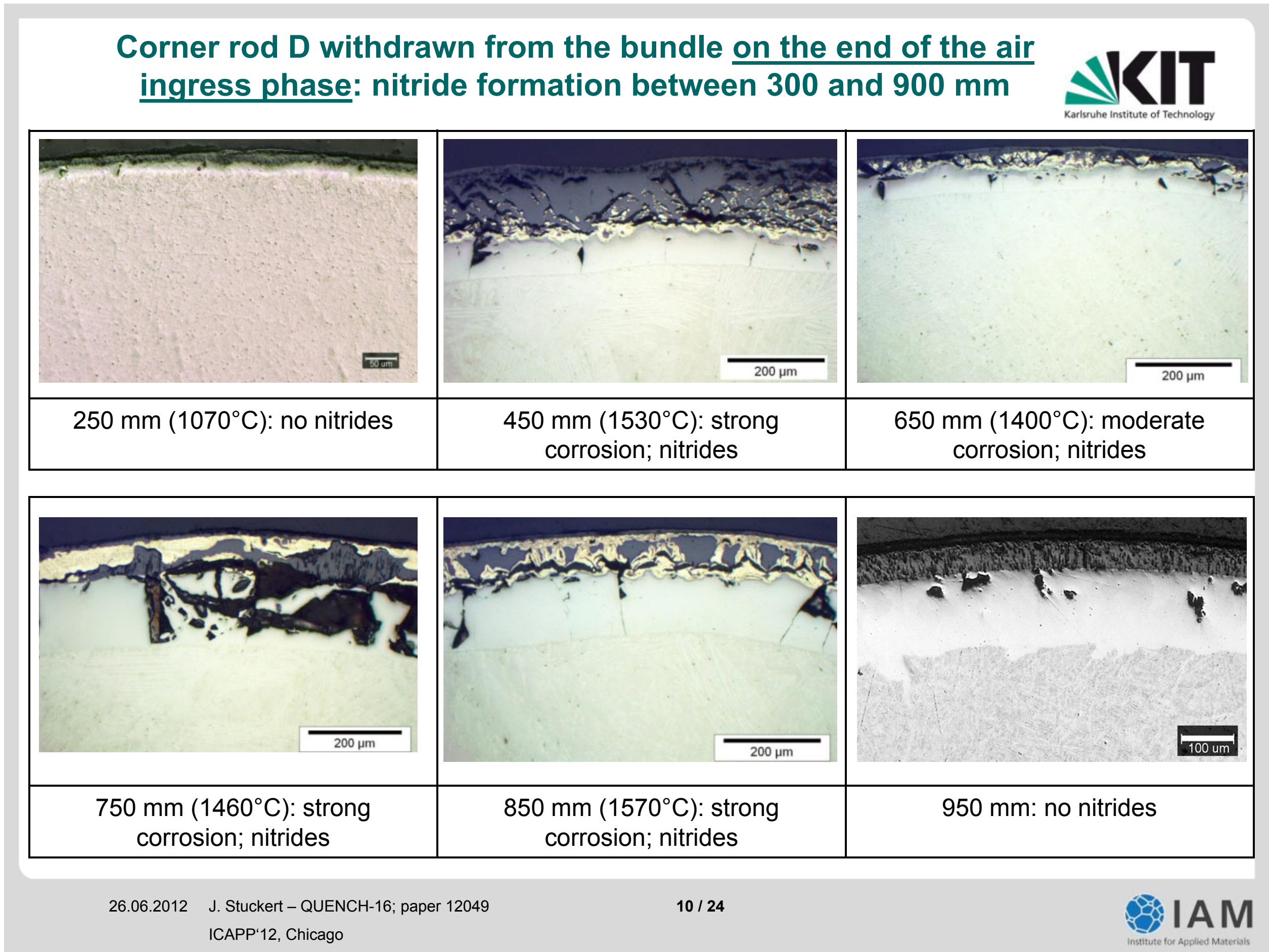


Temperature escalation (above Zr melting point) and cooldown during reflood

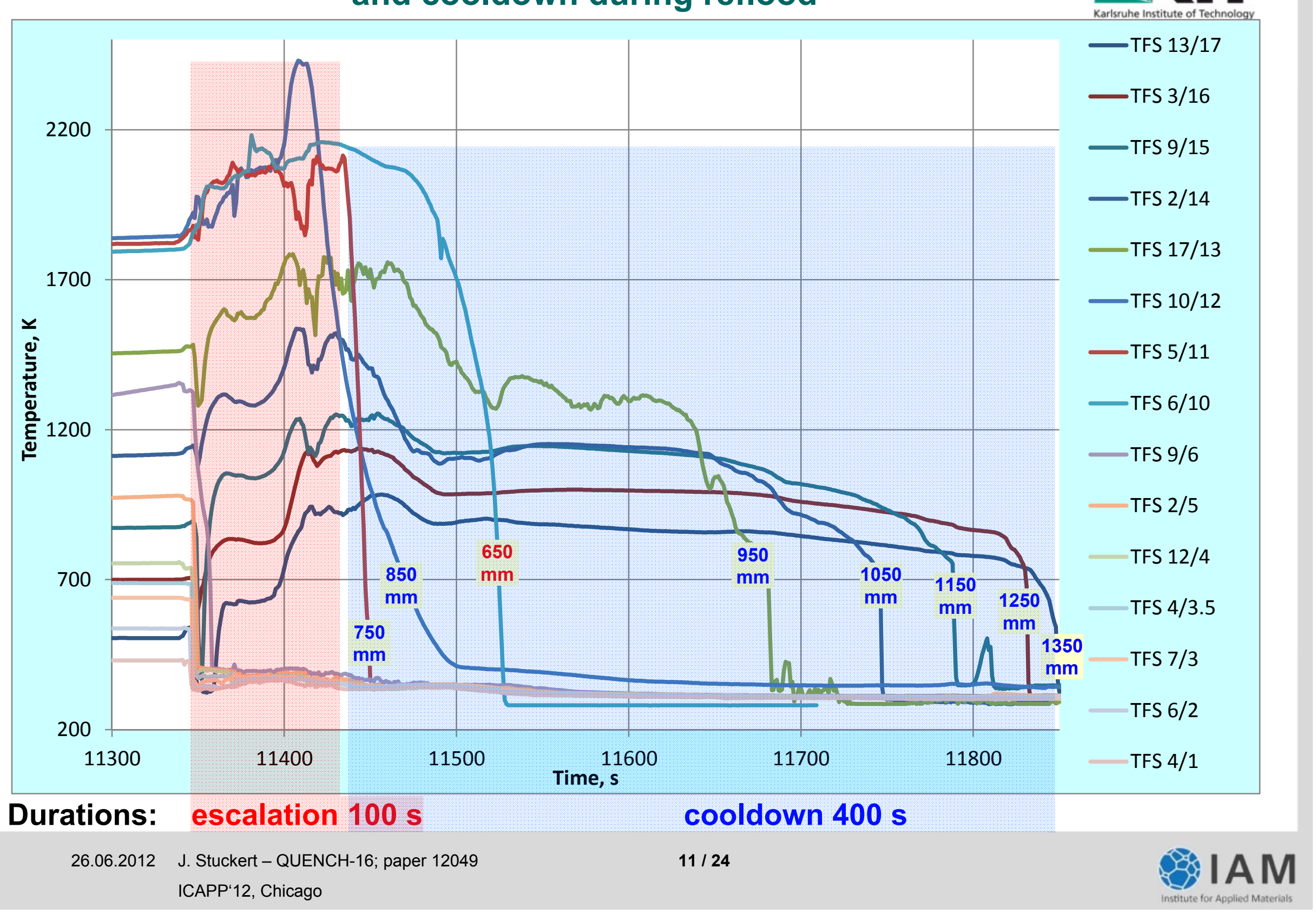


Post-test visual investigations by endoscope introduced at the position of the corner rod B: side view
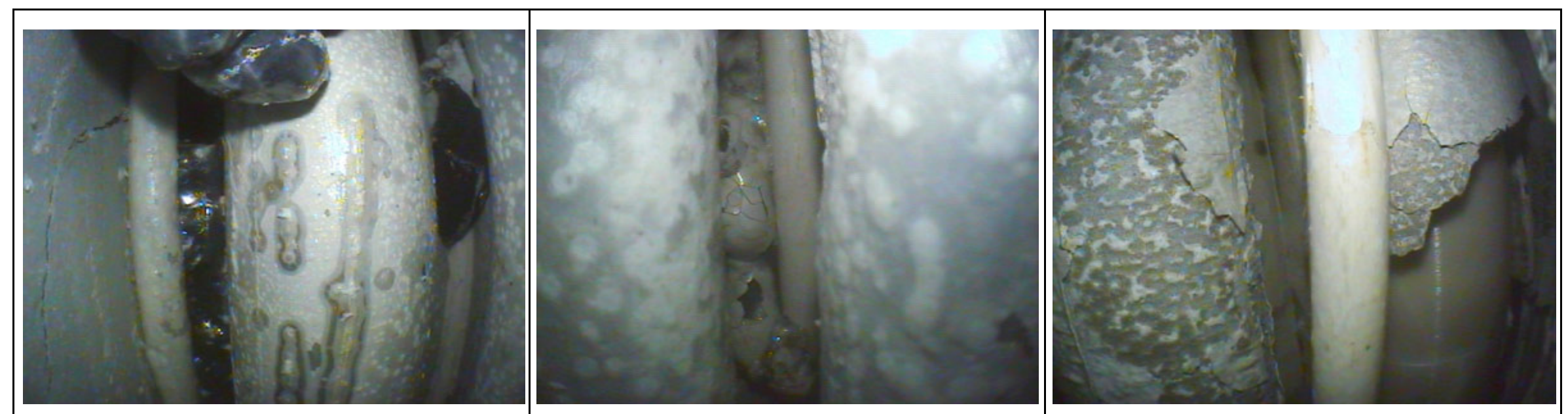

$350 \mathrm{~mm}$ : frozen metallic melt relocated from upper elevations

$420 \mathrm{~mm}$ : oxide shells of melt droplets and rivulets

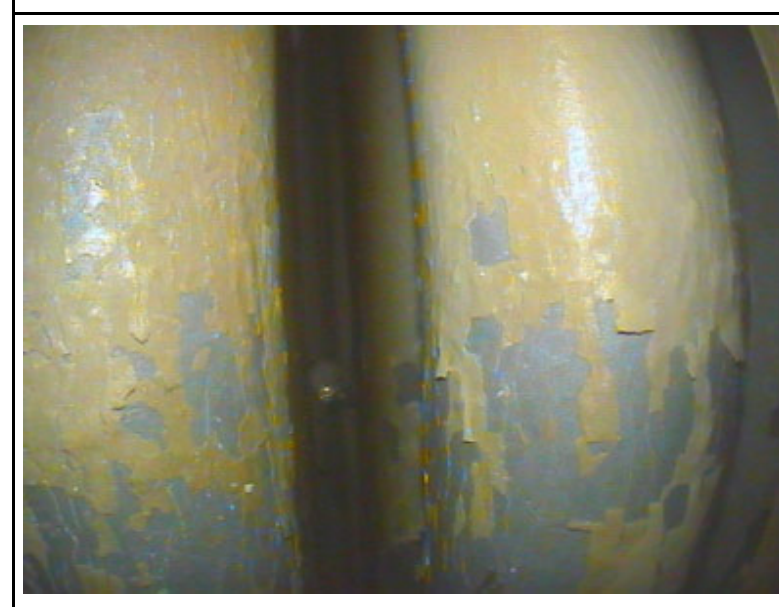

$835 \mathrm{~mm}$ : spalling of outer scale of oxide layer

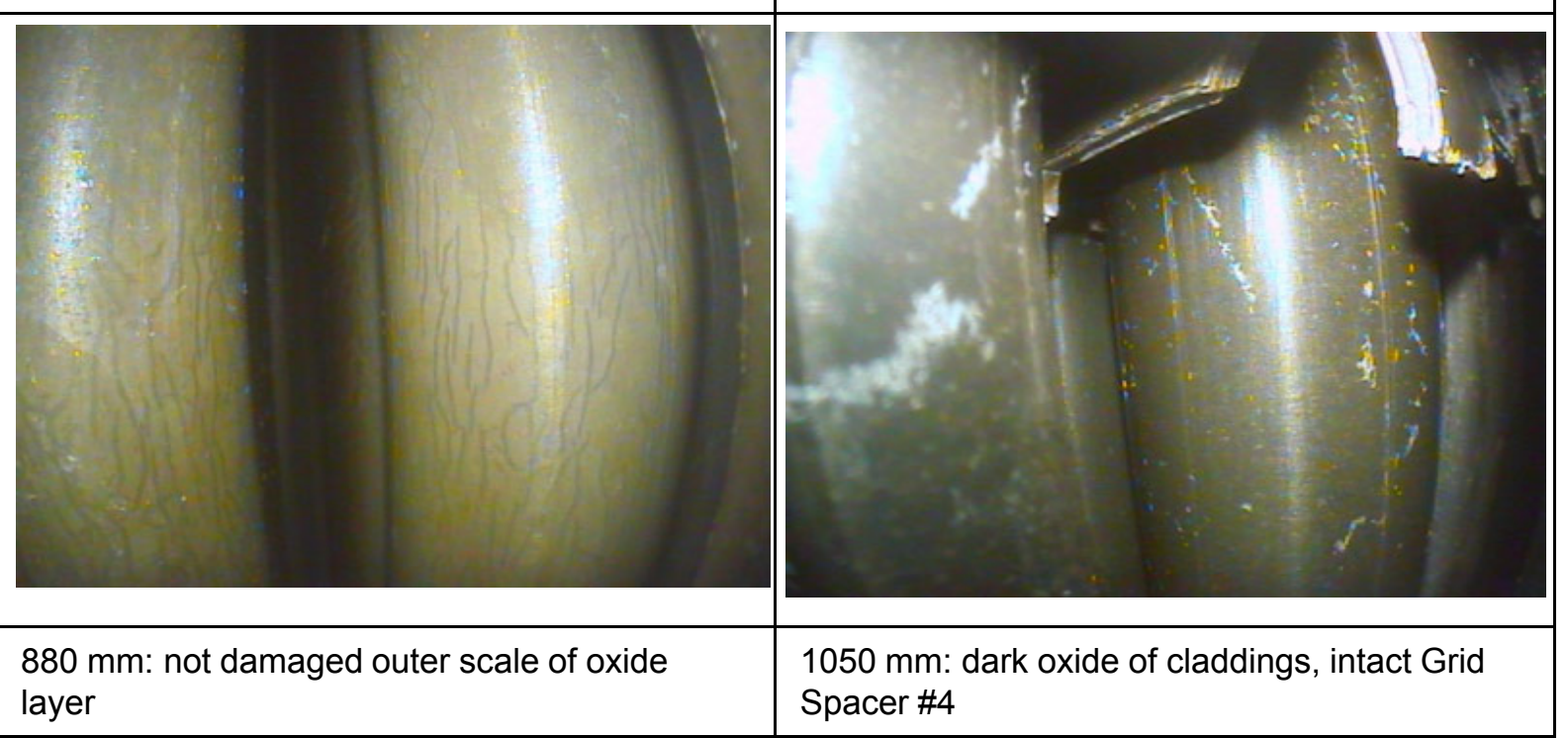

26.06.2012 J. Stuckert - QUENCH-16; paper 12049 ICAPP'12, Chicago

$600 \mathrm{~mm}$ : intensive cladding damaging Spacer \#4

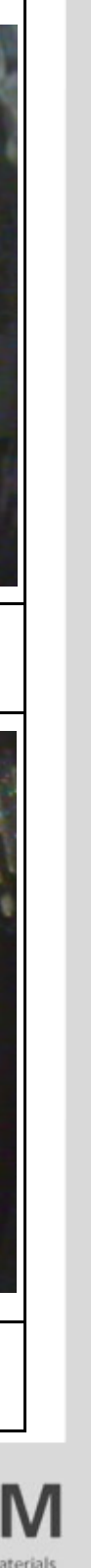




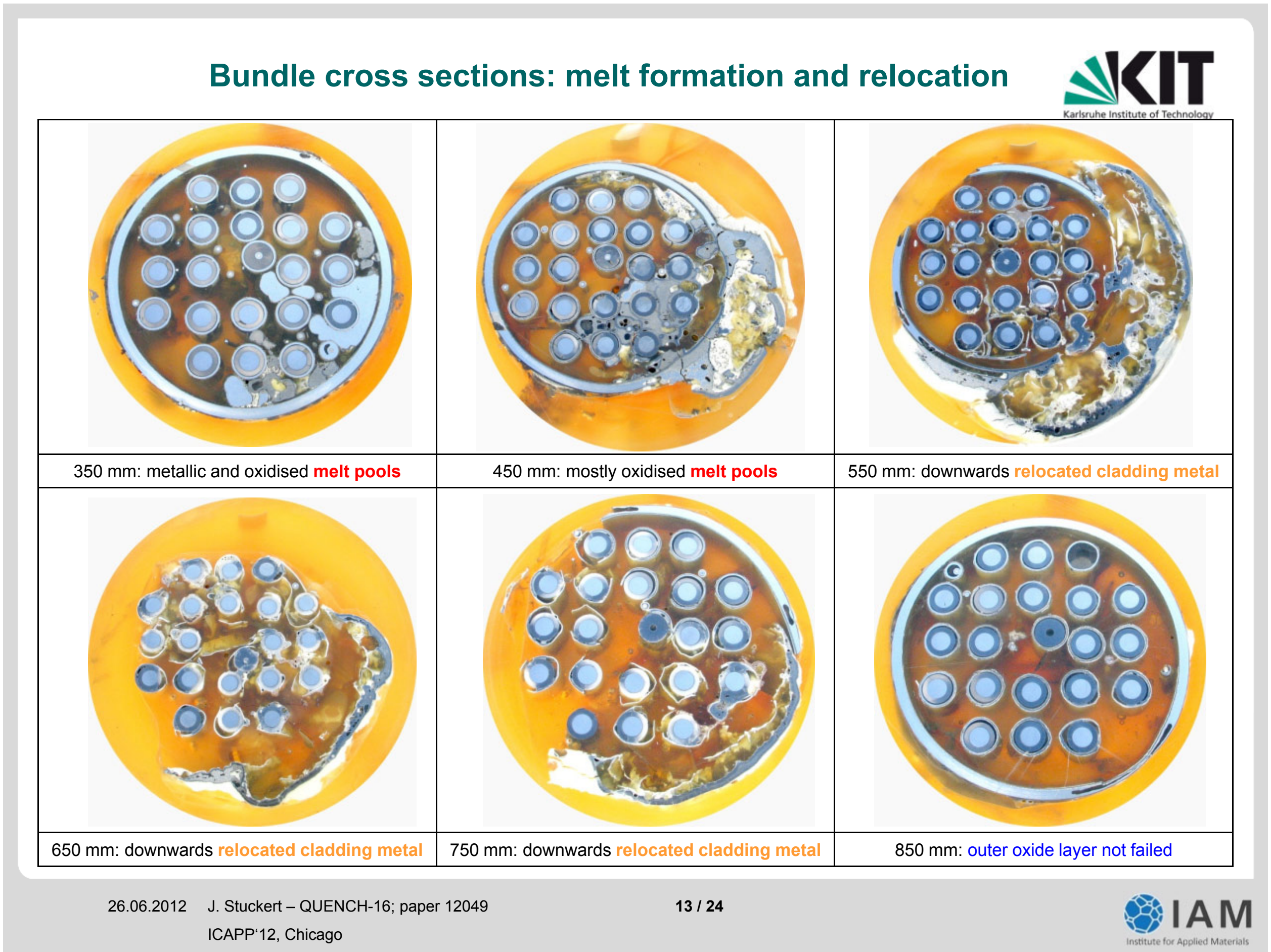


Frozen melt at elevation $350 \mathrm{~mm}$ : not oxidised and oxidised melt

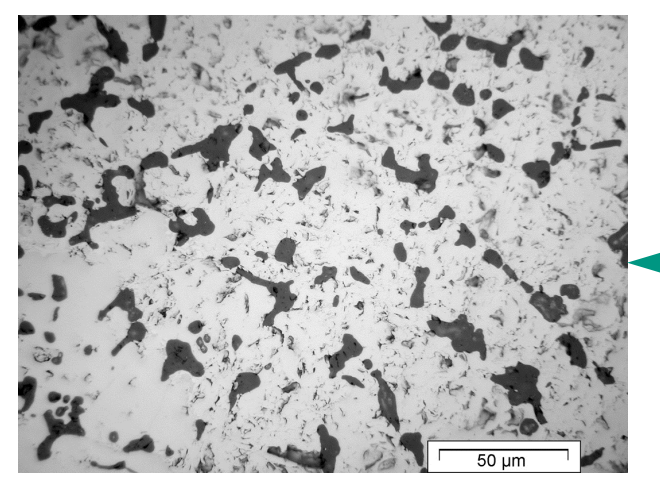

grey porous region; precipitates $10 \%$

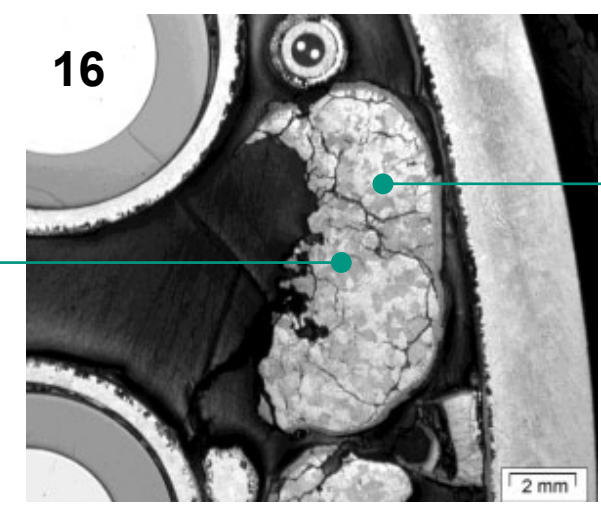

grey and light melt regions

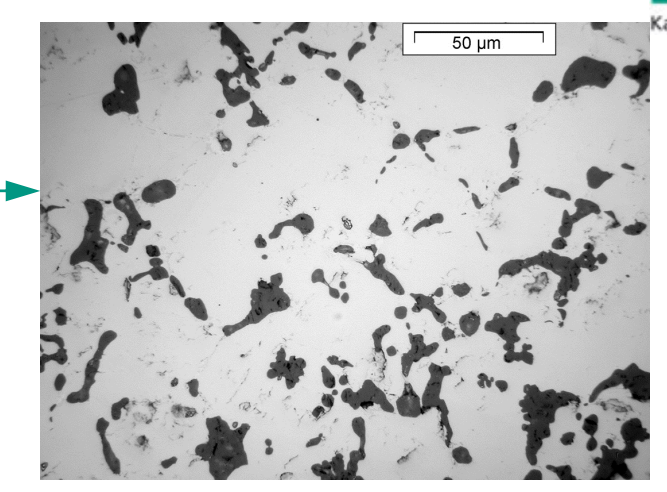

light non porous region; precipitates $10 \%$
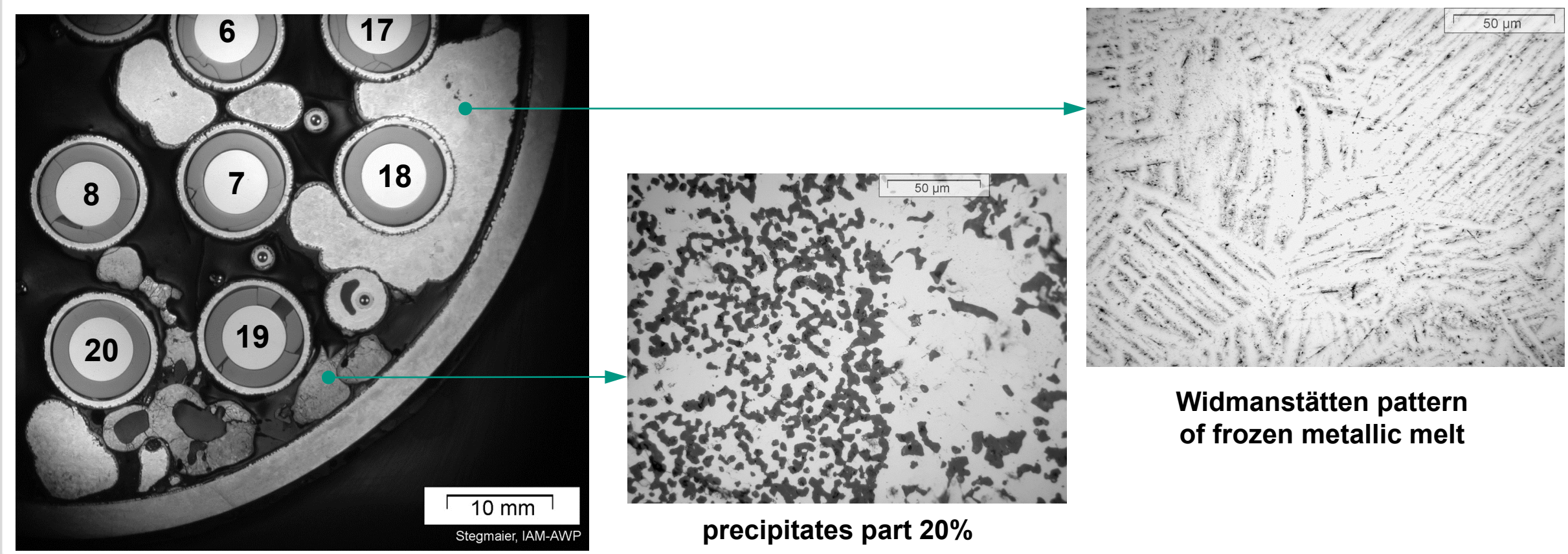

Widmanstätten pattern of frozen metallic melt

26.06.2012 J. Stuckert - QUENCH-16; paper 12049 


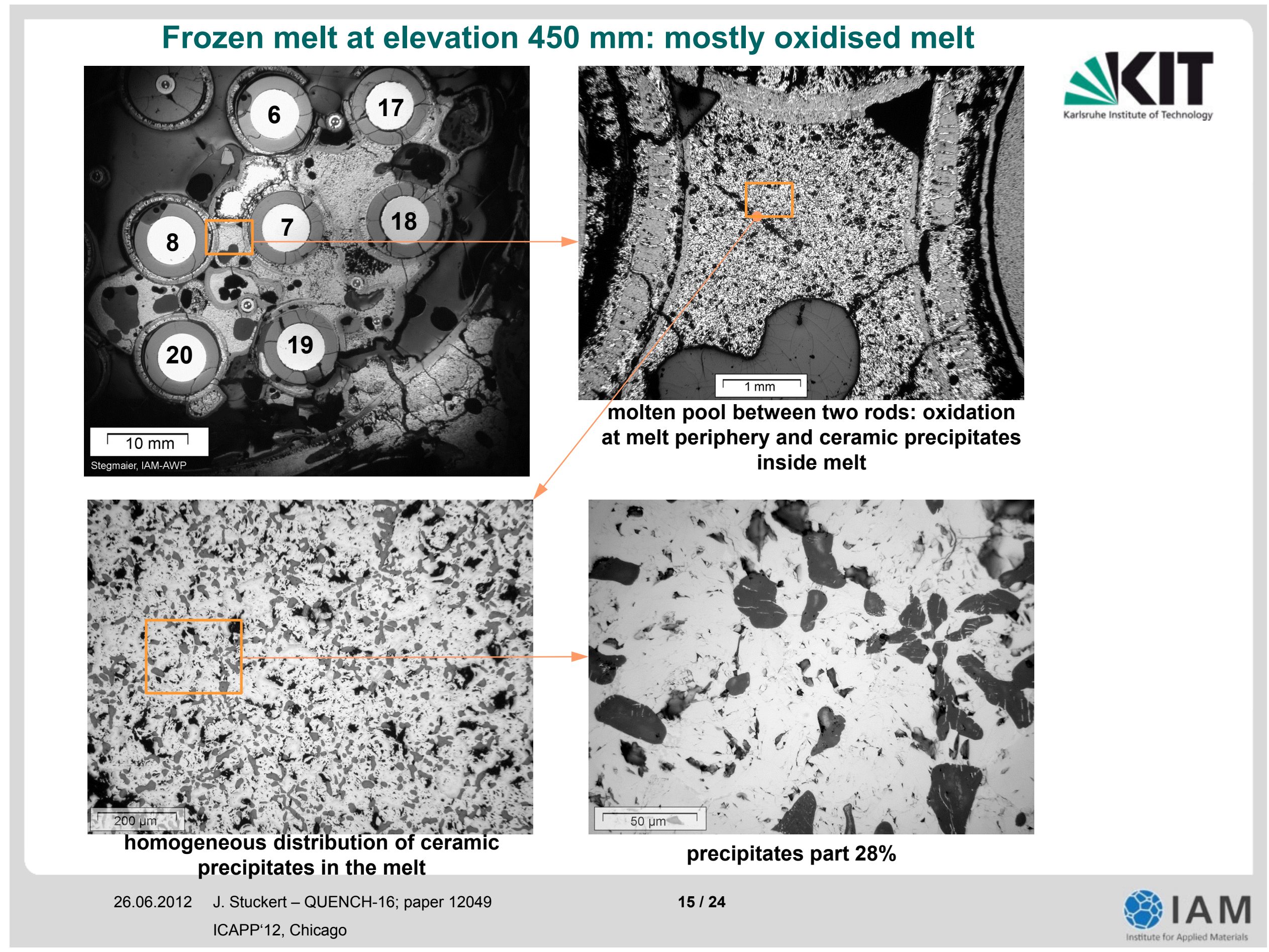




\section{Release of hydrogen and nitrogen during quench phase: data of mass spectrometer}

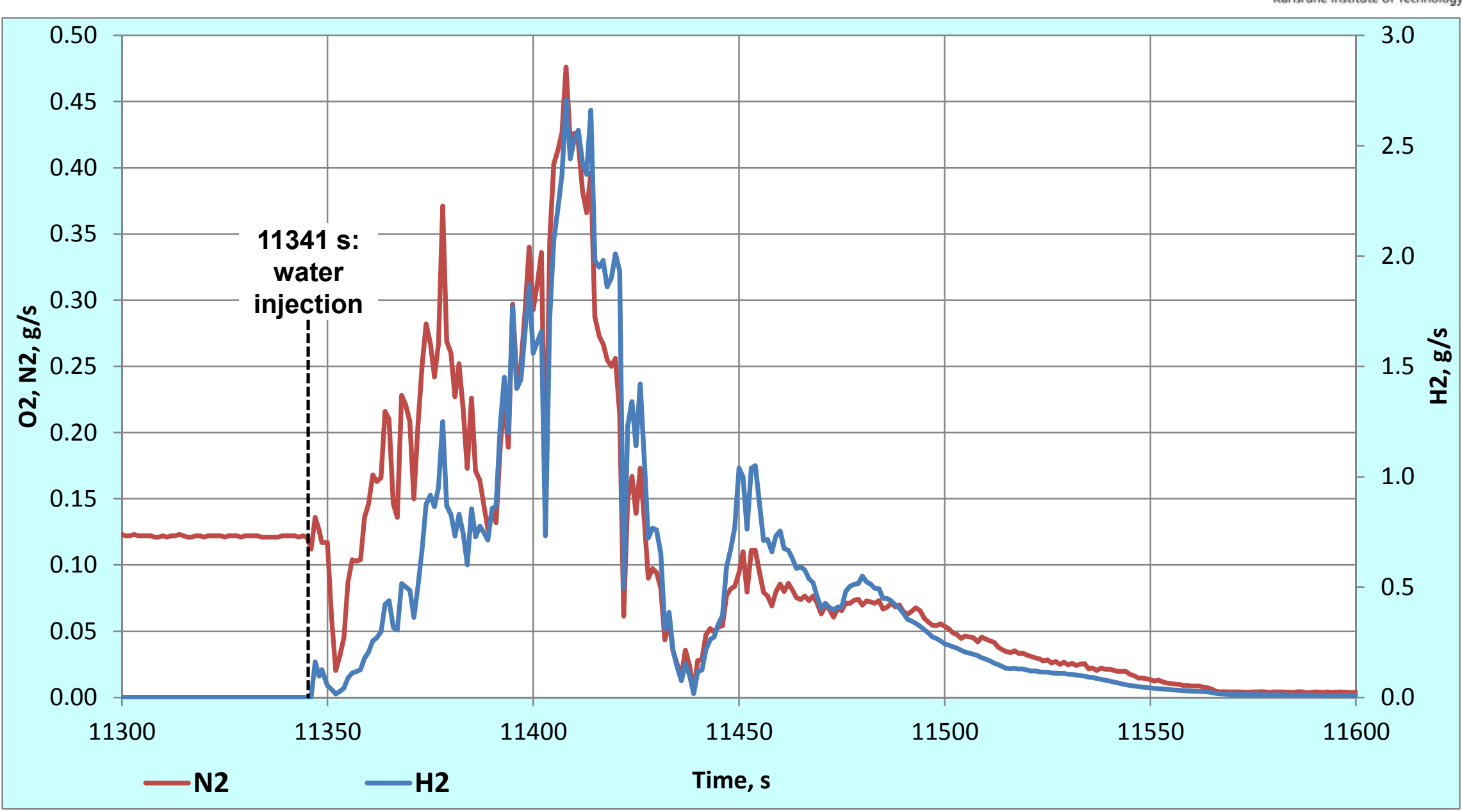

hydrogen release: $128 \mathrm{~g} .3$ main sources:

1) re-oxidation of Zr-nitrides;

2) secondary oxidation of cladding; 3 ) melt oxidation

nitrogen release: $\mathbf{2 4} \mathbf{g}$ from consumed $29 \mathrm{~g}$-> severe nitrides leftover and should be observed 


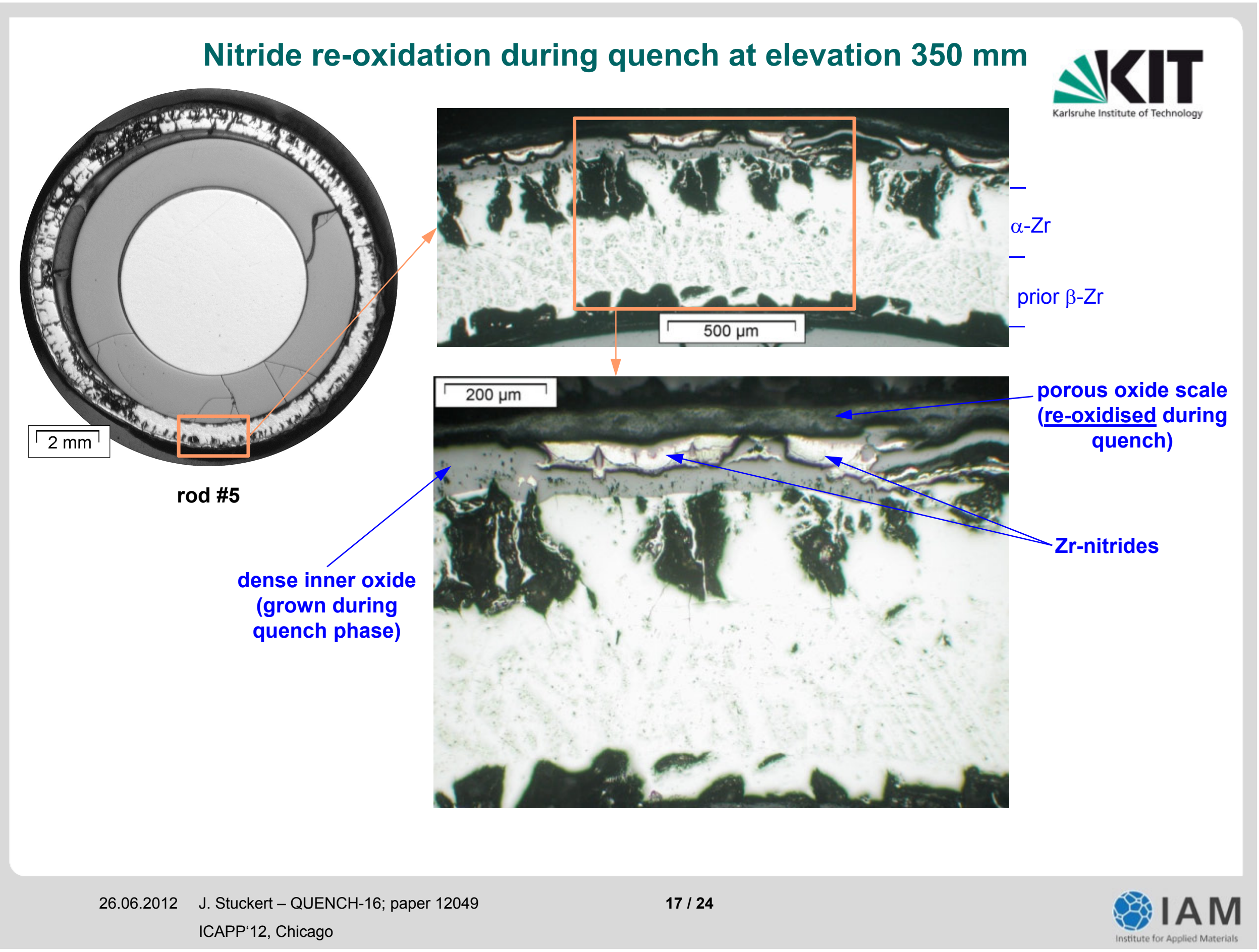




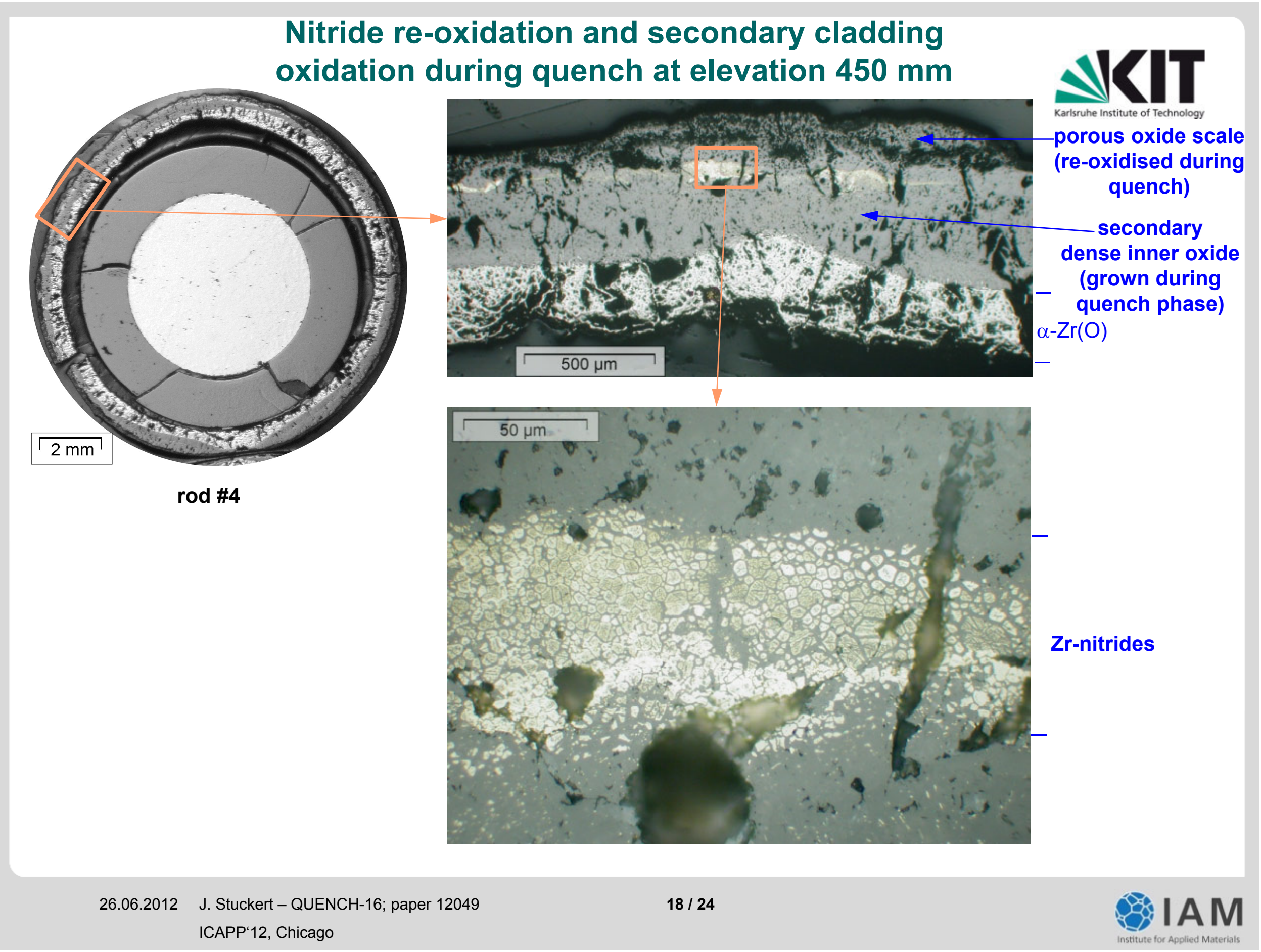




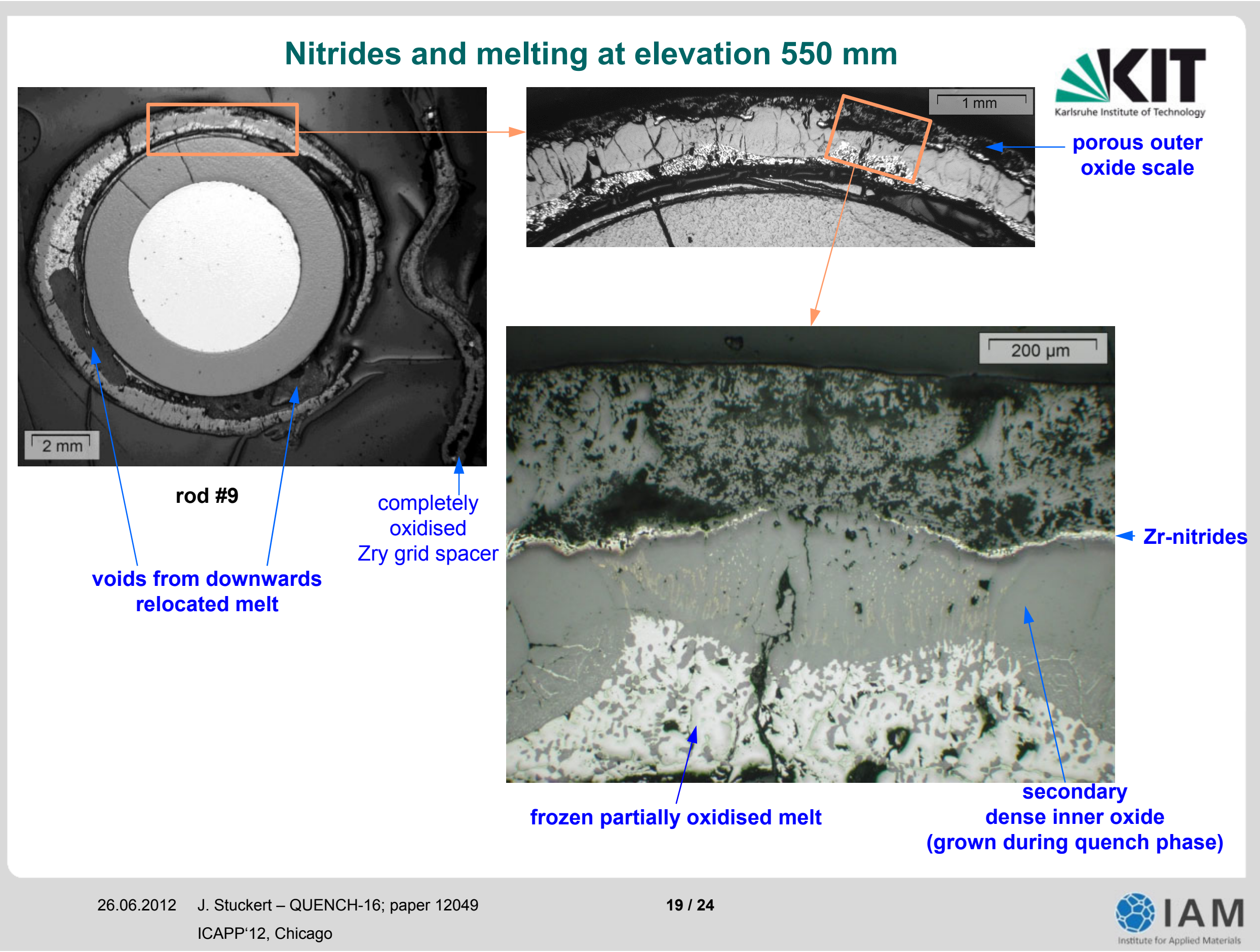




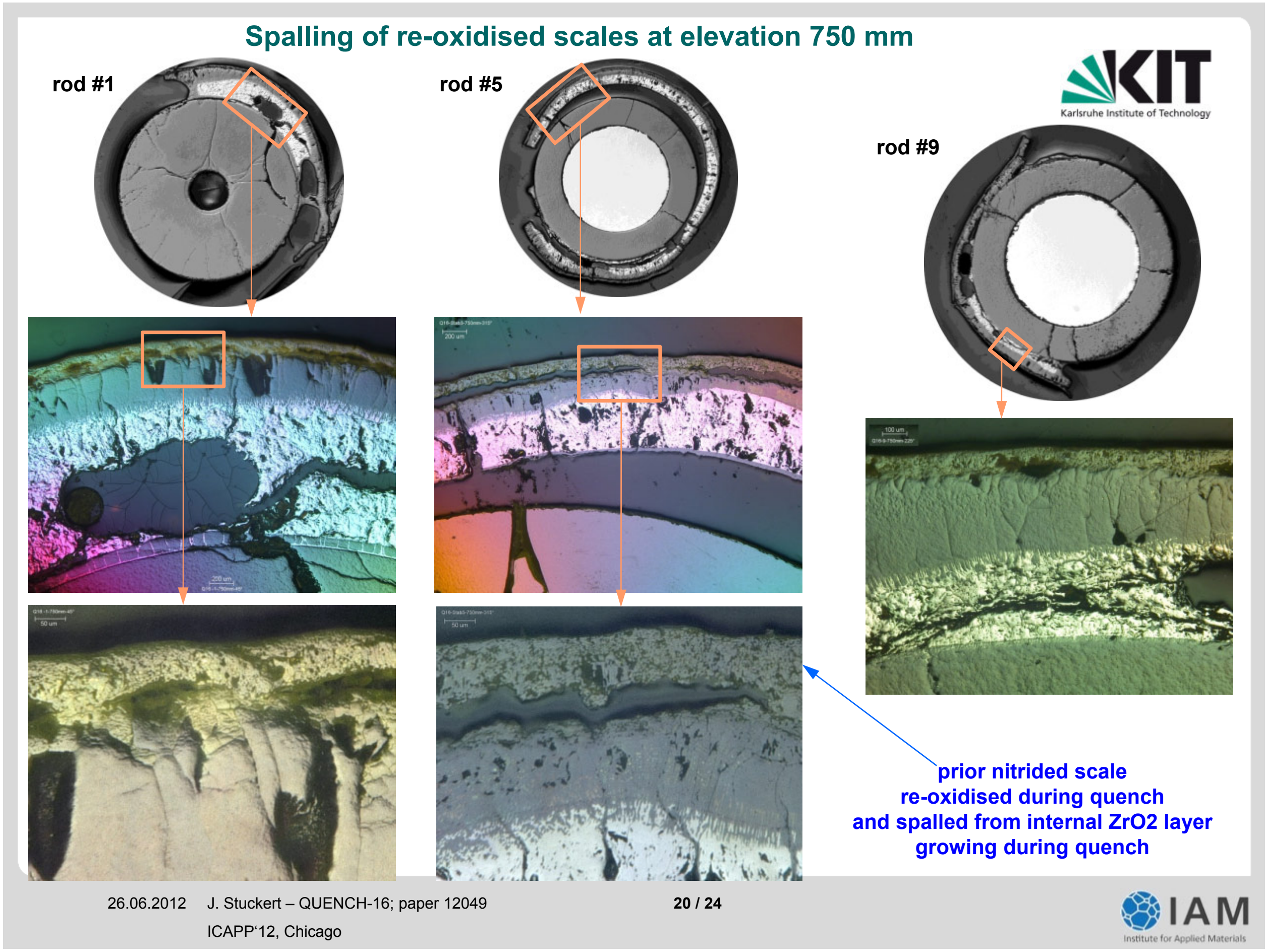




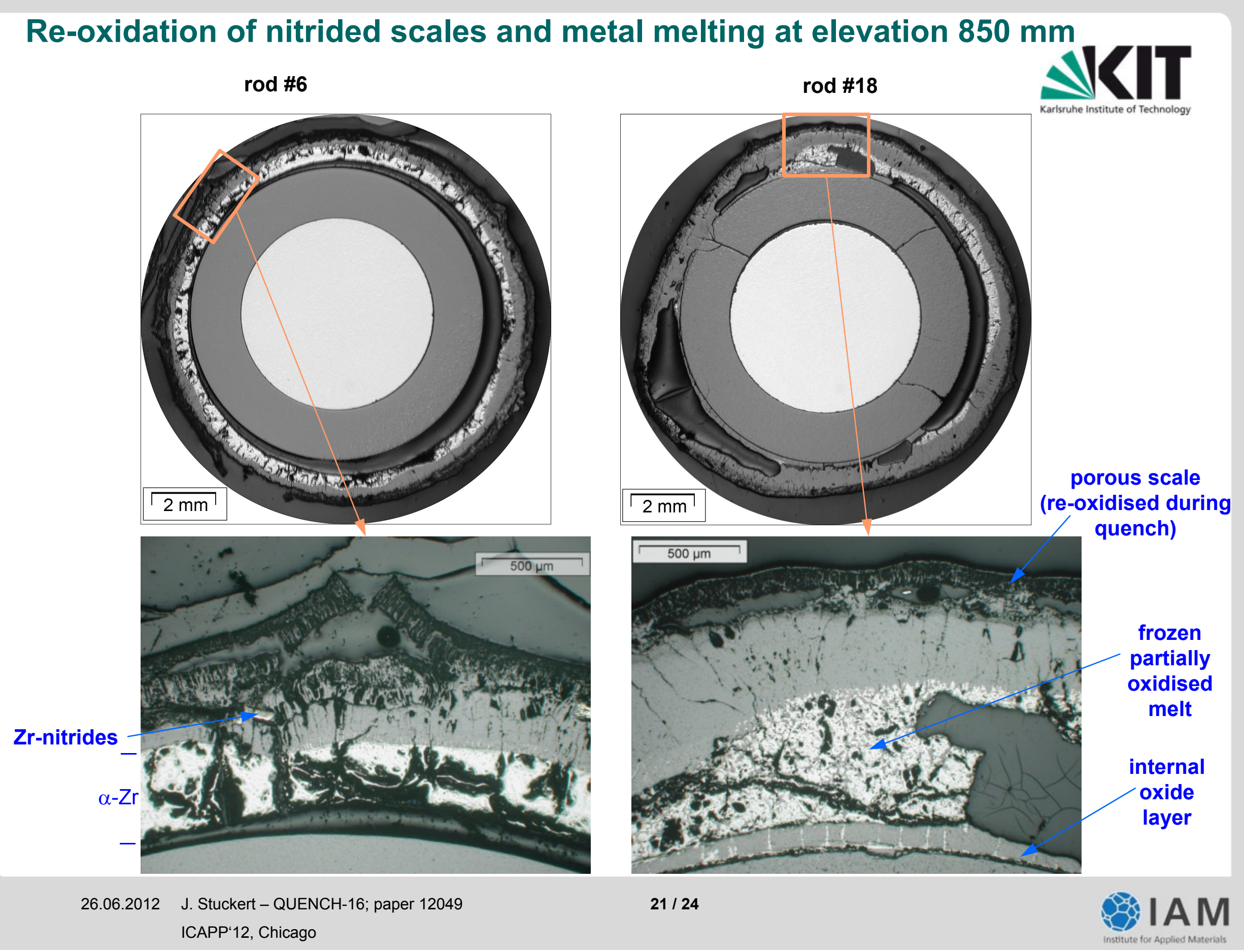




\section{Elevation $950 \mathrm{~mm}$ : no nitrides, no melt formation}

\section{$\mathbb{N}$ CIT}

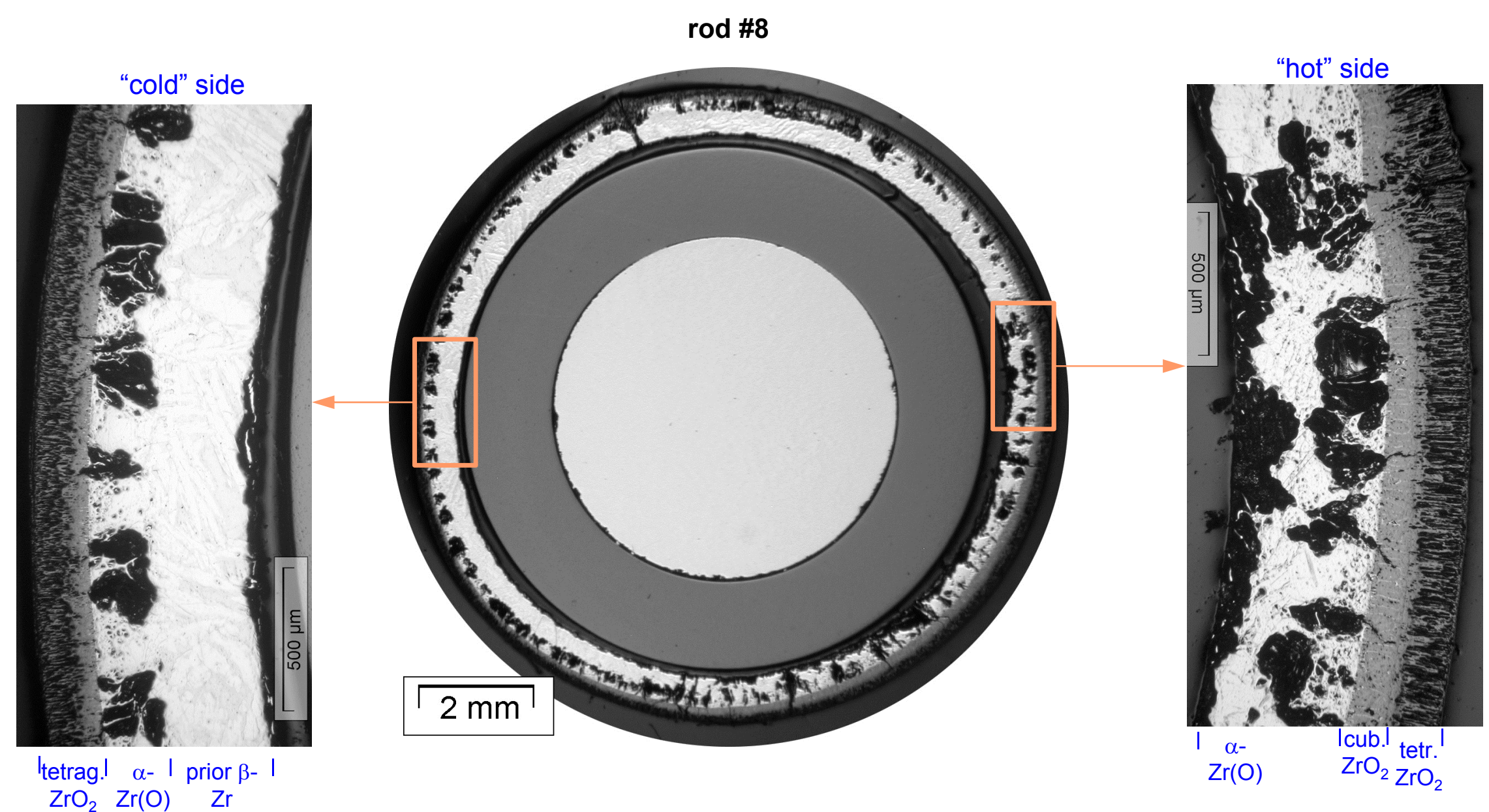




\section{SUMMARY}

- Three typical features of QUENCH-16: moderate pre-oxidation to $135 \mu \mathrm{m}$ of oxide layer (instead $500 \mu \mathrm{m}$ for QUENCH-10), a long period of oxygen starvation during the air ingress phase (800 s instead $80 \mathrm{~s}$ for QUENCH-10), and reflood initiation at temperatures significantly below the melting point of the cladding (1700 K instead of $2200 \mathrm{~K}$ for QUENCH-10).

- A partial consumption of nitrogen during the oxygen starvation, accompanied by acceleration of the temperature increase at mid bundle elevations, caused the formation of porous zirconium nitrides inside the oxide layer at bundle elevations between 350 and $850 \mathrm{~mm}$.

- Immediate temperature escalations to $2420 \mathrm{~K}$ after reflood initiation were caused by massive steam penetration through the porous oxide/nitride scales and intensive reaction with nitrides and especially with metallic cladding. The cooling phase to the final quench lasted ca. $500 \mathrm{~s}$ after achievement of peak temperature.

- $24 \mathrm{~g}$ nitrogen from $29 \mathrm{~g}$, consumed during oxygen starvation period, were released during the quench

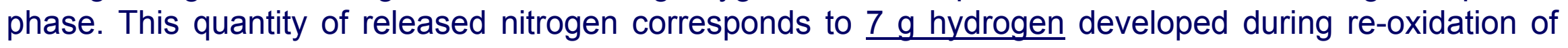
nitrides.

- Image analysis of frozen $\mathrm{Zr}-\mathrm{O}$ melt regions, formed during reflood, allows estimating the hydrogen release due to melt oxidation to $25 \mathrm{~g}$.

- The main part of hydrogen production during reflood $(96 \mathrm{~g})$ was released due to secondary cladding oxidation by steam penetrated through the porous re-oxidized nitrides.

-The total hydrogen production during QUENCH-16 was higher compared to QUENCH-10, i.e., $144 \mathrm{~g}$ (QUENCH-10: $53 \mathrm{~g}$ ), $128 \mathrm{~g}$ of which were released during reflood (QUENCH-10: $5 \mathrm{~g}$ ). 


\section{Acknowledgement}

The QUENCH-16 test was performed in framework of the LACOMECO program at KIT with financial support from the HGF Program NUKLEAR and the European Commission

\section{Thank you for your attention}

http://www.iam.kit.edu/wpt/english/471.php/

http://quench.forschung.kit.edu/ 